\title{
Pengaruh Profitabilitas, Leverage, Ukuran Perusahaan dan Gcg terhadap Firm Value
}

\author{
Rekno Agustina ${ }^{1}$, Kartika Hendra Ts ${ }^{2}$, Endang Masitoh ${ }^{3}$ \\ ${ }^{1,2,3}$ Universitas Islam Batik, Jl. KH. Agus Salim No. 10, Surakarta, Indonesia \\ Correspondence email: reknoagustina02@.gmail.com
}

\begin{abstract}
Abstrak. Penelitian ini bertujuan untuk mengetahui dan menganalisis pengaruh profitabilitas, leverage, ukuran perusahaan dan Good Corporate Governance terhadap Firm Value pada Perusahaan Manufaktur Sub Sektor Property and Real Estate yang terdaftar di Bursa Efek Indonesia periode tahun 2016-2018. Populasi dari penenlitian ini adalah seluruh Perusahaan Sub Sektor Property and Real Estate yang terdaftar di BEI. Penggunaan sampel pada penelitian menggunakan Purposive Sampling dengan kriteria tertentu sehingga diperoleh 70 sampel data untuk diteliti. Data yang digunakan adalah data sekunder yang bersumber dari laporan keuangan. Penelitian ini menggunakan metode Uji Analisis Regresi Linear Berganda. Dari uji tersebut dapat diketaui bahwa Profitabilitas dan Dewan Komiasaris berpengaruh terhadap Firm Value. Sedangkan Leverage, Ukuran Perusahaan dan Komite Audit tidak berpengaruh terhadap Firm Value pada Perusahaan Manufaktur Sub Sektor Property and Real Estate periode tahun 2016-2018.
\end{abstract}

Kata kunci : Leverage; GCG; Firm Value

Abstract. This research aims to know and analyze the impact of profitability, leverage, company size and Good Corporate Governance of Firm Value in the manufacturing company of Sub-sector Property and Real Estate listed on the stock Exchange Indonesia period in 2016-2018. The population of this weaver is the entire Property and Real Estate Sub-sector company listed on the IDX. The use of samples in research using Purposive Sampling with certain criteria thus obtained 70 samples of data to be researched. The data used is secondary data sourced from financial statements. This study used the test method of double Linear regression analysis. From the test, it can be exceeded that profitability and the Commonwealth Council affect the value of the company. Meanwhile, Leverage, company size, and Audit Committee do not affect the company's value in manufacturing company Sub-sector Property and Real Estate period from 2016-2018.

Keywords : Firm Size; GCG; Leverage

\section{PENDAHULUAN}

Perusahaan merupakan suatu lembaga atau organisasi yang dijalankan untuk menyediakan barang atau jasa, dengan tujuan untuk memperoleh keuntungan. Setiap manajemen dalam perusahaan menginginkan agar perusahaannya tetap berkelanjutan (sustainable) sehingga perusahaan selalu berusaha mencari strategi untuk mencapai tujuan perusahaan. Perusahan manufaktur adalah perusahaan yang sering disebut industri atau pabrikan yang kegiatannya melakukan pengelolahan bahan mentah menjadi barang jadi maupun setengah jadi kemudian diperjual belikan kepada masyarakat (Lumentut \& Mangantar, 2019). Di era globalisasi ini perusahaan bergantung pada investor untuk menanamkan modalnya. Maka dari itu perusahaan perlu meningkatkan kulitas dan kuantitasnya supaya dapat menarik para stakeholder. Salah satu dengan meningkatkan laba perusahaan yaitu dengan mengukur nilai perusahaan. Semakin tinggi nilai perusahaan maka semakin tinggi citra perusahaan yang diperoleh. Semua itu didukung juga oleh pihak-pihak internal perusahaan untuk mencapai tujuan tersebut. Perusahaan Property dan Real Estate merupakan perushaan yang bergerak di bidang properti. Memasuki era industri 4.0 ini perusahaan propeti ini banyak diminati karena semakin bertambahnya kebutuhan kontemporer manusia setelah kebutuhan primer dan sekunder terpenuhi. Sealin itu pembangunan ekonomi di Indonesia sedang gencargencarnya maka perusahaan properti banyak dibutuhkan mngenai jasa dan produk yang dihasilkan.

Perusahaan di Indonesia sudah banyak yang menjual sahamnya ke pasar modal atau go public. Ketatnya persaingan di dunia bisnis menjadi pemicu kuat bagi manajemen perusahaan untuk menampilkan nilai terbaik dari perusahaan yang dipimpinnya. Nilai perusahaan yang baik maupun buruk akan berdampak pada nilai pasar perusahaan dan mempengaruhi keputusan investasi para investor untuk menanamkan modal atau menarik investasi dari perusahaan. Nilai perusahaan sangat penting karena mencerminkan kinerja perusahaan yang dapat mempengaruhi persepsi investor terhadap perusahaan (Susanti, Wafirotin, \& Hartono, 2019)

Profitabilitas (Sutrisno, 2012) merupakan kemampuan perusahaan untuk memperoleh keuntungan. Profitabilitas mengukur seberapa besar tingkat keuntungan yang dapat diperoleh oleh perusahaan. Semakin besar tingkat keuntungan perusahaan menunjukkan semakin baik manajemen dalam mengelola perusahaan. Profitabilitas yang tinggi berkaitan dengan prospek perusahaan yang bagus sehingga memicu investor untuk meningkatkan 
permintaan saham. Profitabilitas yang lebih tinggi dapat menyebabkan peningkatan harga saham perusahaan. Harga saham yang lebih tinggi memberikan dampak terhadap nilai perusahaan yang lebih tinggi pula (Ramdhonah, Solikin, \& Sari, 2019).

Leverage dalam penelitian ini diproksikan dengan Debt to Equity Ratio (DER) dengan alasan bahwa DER dapat menunjukkan tingkat risiko suatu perusahaan yang menggambarkan risiko struktur modal, dimana semakin tinggi rasio DER, perusahaan maka semakin tinggi risikonya karena pendanaan dari unsu hutang lebih besar daripada modal sendiri (equity).

Menurut Suharli (2006), Ukuran perusahaan dapat dilihat dari total aset yang dimiliki oleh perusahaan yang dapat dipergunakan untuk kegiatan operasi perusahaan. Jika perusahaan memiliki total asset yang besar, pihak manajemen lebih leluasa dalam mempergunakan asset yang ada diperusahaan tersebut. Jika dilihat dari sisi manajemen, kemudahan yang dimilikinya dalam mengendalikan perusahaan akan meningkatkan nilai perusahaan. Ukuran perusahaan adalah salah satu variabel yang dipertimbangkan dalam menentukan nilai suatu perusahaan. Perusahaan sendiri dikategorikan menjadi dua jenis, yaitu perusahaan berskala kecil dan perusahaan berskala besar (Nurminda, Isynuwardhana, \& Nurbaiti, 2017).

Dewan Komisaris Independen Proksi $G C G$ selanjutnya yaitu dewan komisaris sebagai organ perusahaan bertugas dan bertanggung jawab secara kolektif untuk melaksanakan pengawasan dan memberikan nasihat kepada direksi serta memastikan bahwa perusahaan melaksanakan GCG (Hamdani, 2016). Dewan komisaris independen bertugas untuk menjembatani kepentingan shareholder dan manager akibat perselisihan yang terjadi. Selain itu, tugasnya juga mengawasi kebijakan manajemen dan melakukan reviu atas implementasi strategi jangka panjang yang akhirnya diungkapkan sebagai informasi untuk stakeholder. Dengan demikian, kelengkapan informasi memberikan sinyal positif di mana investor semakin tertarik untuk berinvestasi, sehingga nilai perusahaan meningkat (Lastanti \& Salim, 2018).

Komite audit merupakan badan yang dipilih oleh dewan komisaris untuk bertanggungjawab membantu auditor dalam mempertahankan kemandirian manajemen. Kualitas dan karateristik komite audit berdasarkan keputusan Ketua Badan Pengawas Pasar Modal dan Lembaga Keuangan Nomor: KEP643/BL/2012 yang tercapai menggambarkan legitimasi terhadap responsibilitas komite audit dan pengungkapan informasi yang lengkap, sehingga menimbulkan sinyal positif untuk investor terhadap laporan perusahaan. Dampaknya, nilai perusahaan meningkat.

Kontradiktif dalam penelitian terdahulu maka peneliti menguji kembali pengaruh profitabilitas, leverage, ukuran perusahaan dan good corporate governace terhadap nilai perusahaan pada perusahaan manufaktur sub sektor property and real estate yang terdaftar di bursa efek Indonesia periode 2016-2018.

\section{METODE}

Penelitian ini menggunakan beberapa model regresi linear untuk melihat pengaruh profitabilitas, leverage, ukuran perusahaan, dan Good Corporate Governance yang diproksikan Dewan Komisaris dan Komite Audit. Jenis penelitian ini adalah kuantitatif dan sumber data sekunder yang dieroleh secara tidak langsung dari Perusahaan. Data laporan keuangan Perusahaan Property dan Real Estate di Bursa Efek Indonesia periode tahun 2016-2018.

\section{HASIL DAN PEMBAHASAN \\ Hasil \\ Uji Asumsi Klasik \\ Hasil Uji Multikoloniearitas}

Tabel 1. Hasil Uji Multikolonieritas

\begin{tabular}{cccc}
\hline Variabel & Tolerance & VIF & Kesimpulan \\
\hline Profitabilitas & 0,733 & 1,365 & Tidak terjadi \\
Leverage & 1,099 & 1,365 & Tidak terjadi \\
Ukuran Perusahaan & 1,203 & 1,023 & Tidak terjadi \\
Dewan Komisari & 1,480 & 1,480 & Tidak terjadi \\
Komite Audit & 1,078 & 1,078 & Tidak terjadi \\
\hline
\end{tabular}

Sumber: Data Hasil Penelitian, 2019

Dari tabel 1 menunjukkan tidak ada variabel bebas yang memiliki nilai tolerance kurang dari 0,1 atau $10 \%$ dari hasil perhitungan VIF juga menunjukkan tidak ada variabel bebas yang memiliki nilai VIF lebih 10, oleh karena itu dapat disimpulkan bahwa tidak terjadi multikolonieritas antar variabel.

\section{Hasil Uji Regresi Linear}

Tabel 2. Hasil Uji Regresi Linear

\begin{tabular}{cc}
\hline Model & B \\
\hline (Constant) & 0,379 \\
Profitabilitas & 4,062 \\
Leverage & 0,050 \\
Ukuran Perusahaan & 0,005 \\
Dewan Komisaris & $-0,070$ \\
Komite Audit & $-0,019$ \\
\hline
\end{tabular}

Sumber : Hasil Data Penelitian, 2019

Hasil dari tabel diatas menunjukkan bahwa variabel Profitabilitas, Leverage, dan Ukuran Perusahaan bernilai positif. Ini artinya bahwa Profitabilitas, Leverage dan Ukuran Perusahaan meningkatkan nilai perusahaan.

\section{Hasil Uji Kelayakan Model}

Tabel 3. Hasil Uji Kelayakan Model

\begin{tabular}{ccccc}
\hline$F_{\text {hitung }}$ & $\mathrm{F}_{\text {tabel }}$ & Sig. & Standar & Kesimpulan \\
\hline 15,184 & 2,515 & 0,000 & $<0,05$ & Model Layak \\
\hline Sumber : Hasil Data Penelitian 2019
\end{tabular}


Berdasarkan tabel 3 menunjukkan bahwa nilai $\mathrm{F}$ menghitung berjumlah 15,184 dengan sig. 0,000. Artinya profitabilitas, leverage, ukuran perusahaan dan Good Corporate Governance (GCG) yang diproksikan dewan komisaris dan komite audit memiliki pengaruh signifikan terhadap firm value (nilai perusahaan).

\section{Hasil Uji Hipotesis}

Tabel 4. Hasil Uji Hipotesis

\begin{tabular}{ccccc}
\hline Variabel & $\mathrm{T}_{\text {hitung }}$ & $\mathrm{T}_{\text {tabel }}$ & Sig. & Hasil \\
\hline ROA & 8,053 & $>1,997$ & 0,000 & Diterima \\
DER & 0,709 & $>1,997$ & 0,481 & Ditolak \\
SIZE & 0,206 & $>1,997$ & 0,837 & Ditolak \\
DK & $-4,966$ & $>1,997$ & 0,000 & Diterima \\
KA & $-0,588$ & $>1,997$ & 0,558 & Ditolak \\
\hline
\end{tabular}

Sumber : Data Hasil Penelitian, 2019

Berdasarkan tabel 4 tersebut maka hipotesis 1 menunjukkan bahwa nilai t tabel adalah 8,053 dengan signifikansi 0,000 . Nilai t tabel kurang dari nilai $f$ tabel 1,669 dan nilai signifikansinya $>0,05$. Hasil tersebut menunjukkan bahwa profitabilitas berpengaruh terhadap firm value (nilai perusahaan). Disimpulkan bahwa hipotesis 1 diterima.

Berdasarkan hipotesis 2 menunjukkan bahwa nilai $\mathrm{t}$ tabel adalah 0,709 dengan signifikansi 0,481. Nilai $\mathrm{t}$ hitung 0,709. Nilai t hitung lebih kecil dari $\mathrm{f}$ tabel dan signifikannya $>0,05$. Hasil tesebut menunjukkan bahwa leverage tidak berpengaruh terhadap firm value (nilai perusahaan). Disimpulakan bahwa hipotesis 2 ditolak.

Berdasarkan hipotesis 3 menunjukkan nilai t tabel adalah 0,206 dengan signifikansi 0,873 . Nilai t tabel kuraang dari $\mathrm{f}$ tabel 1,669 dan nilai signifikansinya $>0,05$. Hasil tersebut menunjukkan bahwa ukuran perusahaan tidak berpengaruh terhadap firm value (nilai perusahaan). Disumpulkan bahwa hipotesis 3 ditolak.

Berdasarkan hipotesis 4 menunjukkan bahwa $\mathrm{t}$ tabel adalah $-4,966$ dengan signifikansi 0,00 . Nilai $t$ tabel lebih besar daripada $\mathrm{f}$ tabel dan signifikannya $<0,05$. Hasil tersebut menunjukkan bahwa Dewan Komisaris berpengaruh terhadap firm value (nilai perusahaan). Disimpulkan bahwa hipotesis 4 diterima.

Berdasarkan hipotesis 5 menunjukkan bahwa nilai $t$ tabel adalah $-0,588$ dengan signifikansi 0,558 . Nilai $t$ tabel kurang dari nilai $f$ tabel 1,669 dan nilai signifikansinya $>0,05$. Hasil tesebut menunjukkan bahwa Komite Audit tidak berpengaruh terhadap firm value (nilai perusahaan). Disimpulkan bahwa hipotesis 5 ditolak.

\section{Hasil Uji Determinasi Adjusted $\boldsymbol{R}^{2}$}

Tabel 4. Hasil Uji Determinasi Adjusted $R^{2}$

\begin{tabular}{ccccc}
\hline $\mathrm{R}$ & $\begin{array}{c}\mathrm{R} \\
\text { Square }\end{array}$ & $\begin{array}{c}\text { Adjusted } \\
\text { R Square }\end{array}$ & $\begin{array}{c}\text { Std. Error of } \\
\text { the Estimate }\end{array}$ & Hasil \\
\hline 0,737 & 0,543 & 0,507 & 0,233700 & $50,7 \%$ \\
\hline
\end{tabular}

Sumber: Hasil data Penelitian, 2019
Berdasarkan tabel 4 diatas menunjukkan bahwa hasil perhitungan dari Adjusted R Square sebesar 0,507. Artinya bahwa persentase pengaruh variabel profitabilitas, leverage, ukuran perusahaan dan Good Corporate Governance (GCG) yang diproksikan dewan komisari serta komite audit sebesar 50,7 \%. Sedangkan sisanya yaitu $54,3 \%$ dijelaskan oleh variabel-variabel lainya diluar profitabilitas, leverage, ukuran perusahaan, dewan komisaris dan komite audit.

\section{Pembahasan}

Pengaruh Profitabilitas Terhadap Firm Value

Hasil penelitian dari profitabilitas berpengaruh terhadap firm value (nilai perusahaan). Hal ini menunjukkan bahwa faktor- faktor yang mempenagruhi tingkat kenaikan laba bersih perusahaan akan diikuti peingkatan total aset yang dimiliki. Maka semakin perusahaan mendaptkan profit yang tinggi dapat meningkatkan nilai perusahaan. Sehingga perusahaan sudah memiliki citra yang baik di masyarakat umum yang mana akan menarik para investor untuk menamkan modalnya. Semakin perusahaan memiliki profit yang tinggi maka akan terlihat bahwa hal tersebut menunjukkan bahwa perusahaan.

\section{Pengaruh Leverage Terhadap Firm Value}

Hasil penelitian dari leverage tidak berpengaruh terhadap firm value (nilai perusahaan). Hal ini menunjukkan bahwa modal yang dimiliki perusahaan tidak dapat menutupi kewajiban yang harus ditanggung perusahaan. Penelitian ini di dukung penelitian sebelumnya yang menunjukkan bahwa leverage tidak beroengaruh terhadap nilai perusahaan (Nurminda, Isynuwardhana, \& Nurbaiti, 2017).

\section{Pengaruh Ukuran Perusahaan Terhadap Firm Value}

Hasil penelitian dari ukuran perusahaan tidak berpengaruh terhadap nilai perusahaan. Besarnya total aset ternyata tidak selalu mempengaruhi nilai perusahaan. Hal ini menunjukkan manajemen belum bisa memanfaatkan aset yang dimiliki untuk peningkatan nilai perusahaan. Penelitian ini didukung dengan penelitian sebelumnya seperi yang dilakukan oleh (Susanti, Wafirotin, \& Hartono, 2019) dan penelitian yang dilakukan (Badruddien, Gustyana, \& Dewi, 2017)

\section{Pengaruh Dewan Komisaris Terhadap Firm Value}

Hasil penelitian dari dewan komisaris berpengaruh terhadap nilai perusahaan. Adanya dewan komisaris yang efektif dapat meningkatkan kinerja manjemen perusahaan sehingga dapat meningkatkan nilai perusahaan. Semakin bagus kinerja dewan komisaris maka prospek perusahaanya semakin baik pula. 


\section{Pegaruh Komite Audit Terhadap Firm Value}

Hasil penelitian dari komite audit tidak berpengaruh terhadap nilai perusahaan. Hal ini dapat terjadi karena kinerja komite auditt yang buruk sehingga membuat para investor tidak percaya atas hasil laporan atau informasi yang diperoleh mengenai perusahaan. Penelitian ini didukung oleh penelitian yang dilakukan oleh (Badruddien, Gustyana, \& Dewi, 2017).

\section{SIMPULAN}

Penelitian ini bertujuan untuk menegtehaui pengaruh profitabilitas, leverage, ukuran perusahaan, Good Corporate Governance terhadap nilai perusahaan. Pebelitian ini menggunakan variabel dependen berupa nilai perusahaan yang diukur dengan Price Book Value (PBV). Variabel independen yang digunakan dalam penelitian ini adalah profitabilitas, leverage, ukuran perusahaan dan Good Corporate Governance. Populasi yang digunakan dalam penelitian ini adalah perusahaan property dan real estate yang terdaftar di Bursa Efek Indonesia. Pengambilan sampel menggunakan teknik purposive sampilng yang menghasilkan 34 perusahaan property dan real estate dengan rentang waktu penelitian selama 3 tahun yaitu dari tahun 2016-2018. Penelitian ini menggunakan analisis regresi linier berganda.

Hasil uji regresi membuktikan bahwa secara statistik variabel profitabilitas dan dewan komisaris berpengaruh terhadap nilai perusahaan, sedangkan variabel leverage, ukuran perusahaan dan komite audit tidak berpengaruh terhadap firm value (nilai perusahaan).

\section{DAFTAR PUSTAKA}

Badruddien, Y., Gustyana, T. K., \& Dewi, A. S. (2017, Desember 3). Pengaruh Good Corporate Governance, Leverage, Dan Ukuran Perusahaan Terhadap Nilai Perusahaan (Studi Empiris pada Sektor Industri Barang Konsumsi Di Bursa Efek Indonesia Periode 2012-2015). e-Proceeding Management, 4, 2236.

Hamdani. (2016). Good Corporate Governance Tinjauan Etika Dalam Praktik Bisnis. Jakarta : Mitra Wacana Media.

Hidayat, W. W. (2019). Pengaruh Ukuraan Perusahaan, Return On Equity dan Leverage Terhadap Nilai Perusahaan pada Perusahaan Manufaktur di Indonesia . Forum Ekonomi, 67-75.

Lastanti, H. S., \& Salim, N. (2018). Pengaruh Pengungkapan Corporate Social Responsibility, Good Corporate Governance, Dan Kinerja Keuangan Terhadap Nilai Perusahaan. Jurnal Akuntansi, 5, 27-40.

Lumentut, F. G., \& Mangantar, M. (2019). Pengaruh Likuiditas, Profitabilitas, Solvabilitas, dan Aktivitas terhadap Nilai Perusahaan Manufaktur Yang Terdaftar Di Indeks Kompas100 Periode 2012-2016. Jurnal EMBA, 4, 2601-2610.
Marsha, N., \& Murtaqi, I. (2017). The Effect Of Financial Ratios On Firm Value In The Food And Beverage Sector Of The IDX. Journal of Busineee And Management, 214-226.

Nurminda, A., Isynuwardhana, D., \& Nurbaiti, A. (2017). Pengaruh Profitabilitas, Leveragae, dan Ukuran Perusahaan Terhadap Nilai Perusahaan (Studi pada Perusahaan Manufaktur Sub Sektor Barang dan Konsumsi yang Terdaftar di Bursa Efek Indonesia Periode 2012-2015). e-Proceeding of Management, 542.

Ramdhonah, Z., Solikin, I., \& Sari, M. (2019). Pengaruh Struktur Modal, Ukuran Perusahaan, Pertumbuhan Perusahaan, Dan Profitabilitas Terhadap Nilai Perusahaan (Studi Empiris Pada Perusahaan Sektor Pertambangan Yang Terdaftar Di Bursa Efek Indonesia Tahun 2011-2017). Jurnal Riset Akuntansi dan Keuangan, 7.

Susanti, A., Wafirotin, K. Z., \& Hartono, A. (2019). Pengaruh Good Corporate Governance, Profitabilitas, dan Ukuran Perusahaan Terhadap Nilai Perusahaan Manufaktur Yang Terdaftar di BEI Periode Tahun 2011-2016. Jurnal Ekonomi, Manajemen dan Akuntansi, 4, 18-34.

Susanti, Y., Mintarti, S., \& Asmapane, S. (2018). Pengaruh Struktur Modal Kerja, Kinerja Keuangan Perusahaan, Ukuran Perusahaan dan Kualitas Auditor Eksternal Terhadap Nilai Perusahaan pada Perusahaan Manufaktur Yang Terdaftar Di Bursa Efek Indonesia. 